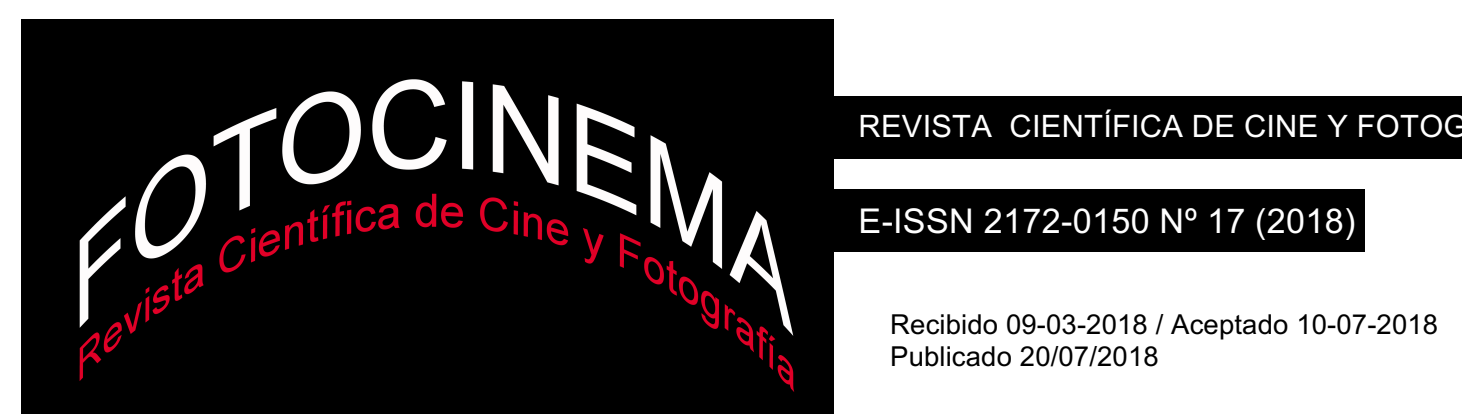

\title{
Narrativas y memorias de la lucha del Ejército Zapatista de Liberación Nacional en el cine documental
}

\section{Narrative and memories of the Zapatista Army of National Liberation in the documentary film}

\section{Delmar Ulises Méndez Gómez}

Instituto Nacional de Antropología e Historia, México delmarmego@gmail.com

\section{Resumen:}

En este escrito presentamos un análisis sobre las formas de narrar y presentar la irrupción y la lucha del Ejército Zapatista de Liberación Nacional (EZLN) en México, por medio del cine documental. Recuperamos tres filmes realizados en la década de los noventa del siglo XX, y entre la primera y segunda década del siglo XXI: 1) Chiapas: paisaje después de la batalla (Irma Ávila, 1994); 2) Autonomía zapatista. Otro mundo es posible (Cristina Hijar y Colectivo AMV, 2008); y Los hombres sin rostro (Elena Korykhalova y Oleg Myasoedov, 2016), de los cuales analizamos qué dicen del EZLN, cómo y quiénes lo presentan. Nos apoyamos en las propuestas del análisis del filme y de los estudios visuales, las cuales nos permiten comprender las relaciones que se establecen entre el acontecimiento revolucionario y su objetivación fílmica, su intervención y persistencia en el presente.

\begin{abstract}
:
In this paper we present an analysis of the ways of narrating and presenting the outbreak and the struggle of the Zapatista Arma of Liberation National (EZLN) in México country, in the documentary films. We recovered three films made between the nineties of the twentieth century and the first decade of the 21st century: Chiapas: paisaje después de la batalla (Irma Ávila, 1994); 2) Autonomía zapatista. Otro mundo es posible (Cristina Hijar y Colectivo AMV, 2008); y Los hombres sin rostro (Elena Korykhalova y Oleg Myasoedov, 2016), to analyse what they said about the EZLN, how it is presented and who do it. We support the proposals of film analysis and visual studies, wich allow us to understand the relationships that are established between the revolutionary event and its film objectification, its intervention and persistence in the present.
\end{abstract}

\section{Palabras clave:}

Chiapas; cine documental; lucha armada; memoria colectiva; pueblos originarios.

\section{Keywords:}

Chiapas; documentary film; armed struggle; collective memory; indigenous people. 


\section{Introducción}

En el estado de Chiapas, ubicado en el Sureste de México, se suscitó uno de los grandes acontecimientos que dejó una profunda marca en la memoria e historia reciente del país: la insurrección del Ejército Zapatista de Liberación Nacional (EZLN), el primero de enero de 1994. Ejército que estaba integrado, casi en su totalidad, por hombres y mujeres tseltales, tsotsiles, ch'oles y tojolabales, que se levantaron en contra del gobierno mexicano por los siglos de exclusión, de olvido, de explotación y de sufrimiento. Exigían, entre otras cosas, el reconocimiento de sus derechos a la vida, la educación, la salud, la alimentación, la tierra y el territorio; asimismo, su lucha estaba anudada a la búsqueda del respeto a las otras formas de gobierno, de organización política y comunitaria, a la posibilidad de ejercer la autonomía. Su irrupción fue de tal trascendencia que era inevitable que los ojos del mundo no voltearan la vista “al rincón más olvidado” de México.

Diferentes actores sociales, motivados por lo que sucedía con el EZLN, viajaron para dar cuenta y llevar a sus lugares de origen, una pequeña versión de lo que alcanzaban a ver y escuchar. Fue uno de los sucesos más registrados, mediatizados y visualizados ${ }^{1}$ en los primeros años del levantamiento. Varios académicos, comunicadores y periodistas de los medios hegemónicos e independientes tomaron las cámaras y los micrófonos para registrar las primeras imágenes de los enfrentamientos que eran transmitidos en la televisión; recogieron los testimonios de hombres y mujeres zapatistas, de la gente que compartía su relato de lo visto y experimentado; siguieron el andar del EZLN. Las grabaciones, que fueron retomadas en los primeros documentales, dieron cuenta de las diferentes versiones de la lucha, que incidieron en las formas de recordar: "cambiando los contenidos de nuestra memoria, cambiando nuestra propia memoria” (Aumont, 1999, citado en Vázquez, 2001, p. 35). La realización documental no fue una acción exclusiva de actores externos a la lucha, puesto que varios

\footnotetext{
${ }^{1}$ Las "visualidades" refieren, de acuerdo con Mitchell (2009), a los modos de mirar, de construir y objetivar la realidad social en imágenes fijas y en movimiento, y que ofrecen un punto singular, particular y/o general de presentar un acontecimiento real o completamente ficticio.
} 
zapatistas se formaron como comunicadores para generar sus propios contenidos, que fueron las fuentes principales de información de las sociedades subalternas. Tomaron los medios porque "los zapatistas necesitaban contar su propia historia” (Halkin, 2006, p. 75). En febrero de 1998, escriben Leyva y Köhler, “se realizó, en territorio autónomo, el primer taller de capacitación de video para las y los jóvenes zapatistas. El interés por las cámaras nació del encuentro de dos mundos diversos -el zapatista y el solidario- en uno de los momentos más álgidos de la guerra contrainsurgente" (2016, p. 326).

Uno de los referentes más importantes en la formación y capacitación de comunicadores populares y autónomos, es el impulsado por Chiapas Media Project/Promedios de Comunicación Comunitaria, organización constituida desde 1998. Hasta el 2006 la organización registró un total de 200 hombres y mujeres indígenas formados en la producción básica de videos ${ }^{2}$. Entre las varias acciones que han llevado a cabo, una de ellas refiere a la forma de realizar los materiales audiovisuales puesto que, en palabras de Halkin (2006, p. 88), “todas las producciones (tanto las de uso interno como las de uso externo) son sometidos a algún tipo de consenso comunitario acerca de temas y contenidos". Se manifiesta una resignificación en los modos de hacer comunicación, distinta al de las prácticas hegemónicas y empresariales.

La realización audiovisual estaba anudada a una de las peticiones que solicitó el EZLN en los Acuerdos de San Andrés: el acceso a los medios de comunicación. "El uso, creación y apropiación de los medios de comunicación por parte de los pueblos indígenas están intrínsecamente vinculados con el proceso de autonomía. Sin la autonomía, los medios de comunicación difícilmente serán apropiados” (Hernández y Vera, 1998, p. 151). En este sentido, la apropiación de las cámaras de video tenía un sentido no sólo de carácter comunicativo, sino político, al significarlas como un dispositivo de "enunciaciones otras", de "visualidades otras" (León, 2010). Los documentales realizados por los comunicadores zapatistas ampliaron e

2 Véase Halkin, A. (2006). "Fuera de la óptica indígena: Zapatistas y Videístas Autónomos". Revista Chile de Antropología visual, núm. 7, pp.71-92. 
interpelaron el campo informativo y comunicativo de lo que se decía y presentaba de la lucha. La realización audiovisual, como señalan Leyva y Köhler, "es parte medular de sus prácticas autonómicas y de resistencia" (2016, p. 327). Entre 1998 y 2007 realizaron 29 videos en los que plantean diferentes procesos logrados en los primeros quince años de camino.

Con lo anterior, enfocamos nuestro análisis en la reconstrucción de la insurrección zapatista en Chiapas por medio del cine documental. Nuestros objetivos principales son: reflexionar qué se dice de la lucha, cómo se dice, qué elementos narrativos y visuales componen los filmes documentales, quiénes son los autores de las obras audiovisuales y cuáles son los usos que éstos tienen en la actualidad. El cine ha sido uno de los recursos del lenguaje para reconstruir los grandes acontecimientos de la historia. Permite dejar una huella, una impresión de algo sucedido en el pasado y que por medio del documental, como en este caso, se busca desvelar en parte.

\section{Marco metodológico}

Para el análisis de las narrativas de la lucha del EZLN retomamos tres documentales: 1) Chiapas: paisaje después de la batalla (Irma Ávila, 1994); 2) Autonomía zapatista. Otro mundo es posible (Cristina Hijar y Colectivo AMV, 2008); y Los hombres sin rostro (Elena Korykhalova y Oleg Myasoedov, 2016). Dichos filmes los recuperamos porque tienen una característica singular: fueron realizados por actores "externos" a la lucha zapatista. No obstante, cada uno tiene su propia particularidad. El primero, se realizó en el primer año de la irrupción zapatista, da cuenta de las primeras imágenes y los discursos que construyen la imagen colectiva de la lucha. El segundo fue realizado en la primera década del 2000, en el que se comparten las formas de trabajo y de organización de las Juntas de Buen Gobierno, la consolidación de los Caracoles y los municipios autónomos. En el tercero, filmado entre el 2014 y 2016, se hace un recuento de los acontecimientos más recientes de lucha zapatista. Para este primer esbozo, por falta de espacio, no hacemos un análisis de los documentales realizados por los comunicadores zapatistas, sin embargo, será desarrollado en otro 
momento. Los audiovisuales son, en un primer momento, desglosados por medio de la aplicación del découpage, instrumento de análisis del film nombrado por Aumont y Marie (1990) que permite la segmentación de las películas en cuanto a su forma (secuencias, planos, movimientos de cámara, sonido) y contenido (escenas, temas y transcripción de los diálogos). El découpage se empleó para segmentar los materiales en escenas con el objetivo de identificar los temas, diálogos y contextos de manera agrupada antes que aislarlos en su singularidad.

Una vez que segmentamos en escenas las películas, e identificamos los temas, diálogos y contextos, el análisis se realizó con la propuesta de Casetti y di Chio (1990). De acuerdo con estos autores, el análisis del film se desarrolla a partir de cuatro grandes partes: 1) El análisis de los componentes cinematográficos; 2) El análisis de la representación; 3) El análisis de la narración; y 4) El análisis de la comunicación. El primero, se centra en los signos, códigos visuales y sonoros del film; el segundo, en la reconstrucción de una realidad a partir de un acontecimiento "real", y en la construcción de otra distinta a su referente; el tercero, refiere a los acontecimientos, las acciones de los personajes y las transformaciones que éstos manifiestan en la trama; el cuarto, trata sobre las formas que comunica el film y los puntos de vista de quien lo realiza. De la propuesta de Casetti retomamos únicamente el análisis de la narración y el análisis de la comunicación.

\section{La irrupción del EZLN. Chiapas: paisaje después de la batalla}

Uno de los primeros documentales que se apoya de las primeras imágenes del movimiento zapatista, grabadas por reporteros y periodistas, fue Chiapas: paisaje después de la batalla 3 (1994) realizado por Irma Ávila Pietrasanta, producido por TV UNAM. El filme entreteje diferentes voces que ofrecen perspectivas y argumentos de la irrupción zapatista. La directora es la narradora principal del documental quien, con voz en off, ofrece datos estadísticos y contextuales que nos permiten entender el grado de marginalidad y pobreza en los pueblos originarios de Chiapas. La primera

3 Disponible en línea: https://www.youtube.com/watch?v=xgUSw_rulvE 
secuencia de la película inicia con la descripción de las condiciones de vida de las familias indígenas:

Antes del 31 de diciembre de 1993, pocos mexicanos conocían los siguientes datos: Chiapas tiene el índice más alto de mortalidad más alto en el país, existe una cama de hospital por cada tres mil habitantes, el 42 por ciento de las viviendas en el estado Chiapas carecen de drenaje, 80\% de la población Chiapaneca gana diez pesos diarios (min. 00:51).

Mientras escuchamos a la directora, una serie de imágenes, compuestas por planos generales, fijos y lentos, refuerzan visualmente los datos duros, se aprecia el rostro de ancianos, el caminar lento de las niñas con los pies descalzos, las casas de madera a punto de desplomarse, a hombres y mujeres en cuya cara se reconoce una profunda tristeza.

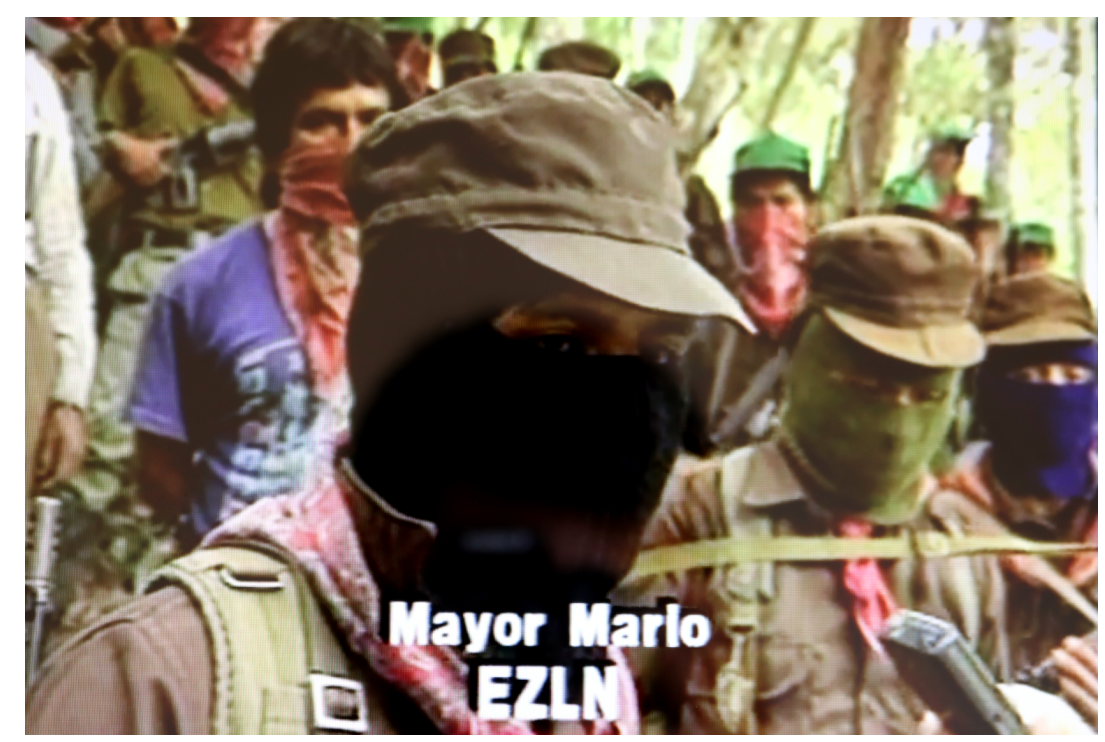

F1. Palabras del Mayor Mario. Irma Ávila, Chiapas: paisaje después de la batalla, 1994, min: $02: 12$.

Hay una intención de la realizadora de sensibilizar a los espectadores y dar a entender los motivos de la lucha que, en la escena siguiente, con la presentación del Mayor Mario, frente a las cámaras de los periodistas, expresa los argumentos del por qué decidieron levantarse. Mientras habla, sus compañeros parados alrededor de los árboles escuchan con atención sus palabras: "Nosotros los pobres hemos declarado la guerra por varias causas, y quiero que pregunten al rato a todos mis soldados y mis gentes pobres que 
están aquí a mi alrededor, nosotros hicimos esta guerra contra el gobierno, porque ya no aguantamos la miseria” (min. 02:13). La directora nuevamente habla y se ubica en lo que acontece el día en que irrumpe el EZLN:

El primero de enero de 1994, despertamos en otro país, el día en que íbamos a celebrar la entrada al primer mundo, retrocedimos un siglo, creímos y quisimos ser norteamericanos, y nos salió al paso nuestro destino centroamericano. La sangre derramada clama poner fin a la matanza, no se puede acabar con la violencia de los sublevados si no se acaba con la violencia de los opresores (min. 02:57).

En otra escena, se insertan las primeras imágenes de la ocupación de la presidencia municipal de San Cristóbal de las Casas por los zapatistas. Paralelamente, la directora incluye imágenes de archivo de la Revolución mexicana para hacer un comparativo sobre la situación social, política y económica entre la primera y segunda década del siglo XX con la última del mismo siglo. Posteriormente a la primera parte que se focaliza en los datos estadísticos del desarrollo social en Chiapas, se construye una segunda parte en la que las voces de los zapatistas, académicos, activistas y poetas explican los motivos que provocaron la creación y el levantamiento del EZLN, entre los que destacan Eraclio Zepeda, Concepción Villafuerte, Araceli Burguete y Samuel Ruiz. Uno de los primeros actores en aparecer es la maestra Araceli Burguete, integrante del Frente Independiente de Pueblos Indios, quien menciona el punto donde surge la mayor movilidad y el conflicto en Chiapas:

Se habla con bastante imprecisión de Los altos de Chiapas [...] no son los que están en zona de conflicto, el conflicto se da, principalmente, en la región selvática, que es una región que en los últimos treinta años ha sido zona de recepción de inmigrantes, es por eso que los indígenas levantados en armas sean tseltales, tsotsiles, choles, tojolabales y también mestizos (min. 08:04).

En otra secuencia, la directora inserta imágenes de la cámara de diputados y explica una de las problemáticas sobre el derecho a la tierra: "Las reformas al artículo 27 constitucional, hacen posible la desintegración y privatización de la propiedad ejidal y comunal, abriendo camino para que sólo diez mil novecientas treinta y tres haciendas puedan ser propietarias de todas las 
tierras agropecuarias y forestales del país" (min. 10:15). Esta escena busca enfatizar el problema agrario en Chiapas y el control de los terratenientes y ganaderos, quienes eran apoyados por el gobierno mexicano, y que desfavorecían a los pueblos originarios quienes han sido negados no sólo por el Estado, sino por la sociedad civil al desconocer los orígenes prehispánicos y étnicos del país:

En México uno de cada cuatro mexicanos es indígena [...] existen 56 grupos étnicos distribuidos en todo el territorio nacional, la raíz indígena de nuestro país ha sido reconocida como la mayor riqueza que poseemos, sin embargo, nuestro presente indio, ese presente vivo, concreto y palpable, es visto como un obstáculo para el desarrollo (min. 11:54).

En otras de las escenas se presenta a la Capitán Irma, quien demuestra el agenciamiento político que asumían las y los zapatistas al expresar su sentir respecto a su lucha: "a nosotros nos dicen perros, con su gorra y pasamontañas, indios, que no sabemos nada, que no sabemos nada porque el gobierno no nos da nada, por eso estamos ignorantes" (min: 14:00). Hay una intención de reivindicar la lucha de las mujeres zapatistas, y de visibilizar el racismo y la discriminación existente hacia los hombres y mujeres de pueblos originarios. Esta idea es reforzada con la escena siguiente donde aparece el obispo Samuel Ruiz, quien fue el mediador en los acuerdos de paz entre el gobierno mexicano y el EZLN; comparte su perspectiva del sentido político y religioso del levantamiento:

Vemos en el indígena el pobre por excelencia, el que ésta en el piso más bajo de todo el edificio social, por tanto, al cual Dios se identifica, el Dios de los pobres [...] que no sólo viene a remedir a su sometimiento, de su privación y sufrimiento, anunciando una vida y una resurrección, sino que los hace gestores de su propia historia" (min: 17:55).

Anudado al testimonio del obispo Samuel Ruiz, se reconstruye una secuencia del EZLN en calles de San Cristóbal de Las Casas, y el cerco militar que se había situado en la ciudad. La directora vuelve a tomar la palabra para dar constancia de cómo la lucha zapatista no tuvo presencia sólo a nivel local y nacional, sino internacional, y que el primero de enero del 94 se leía la 
Primera Declaración de la Selva Lacandona en la que manifestaron diez demandas: "trabajo, tierra, techo, alimentación, salud, educación, independencia, libertad, justicia, democracia y paz" (min: 36:12). Mientras se escuchan los diez puntos de la Primera Declaración, una serie de imágenes de archivo de lucha zapatista, de hombres y mujeres en movimiento, refuerza la información proporcionada.

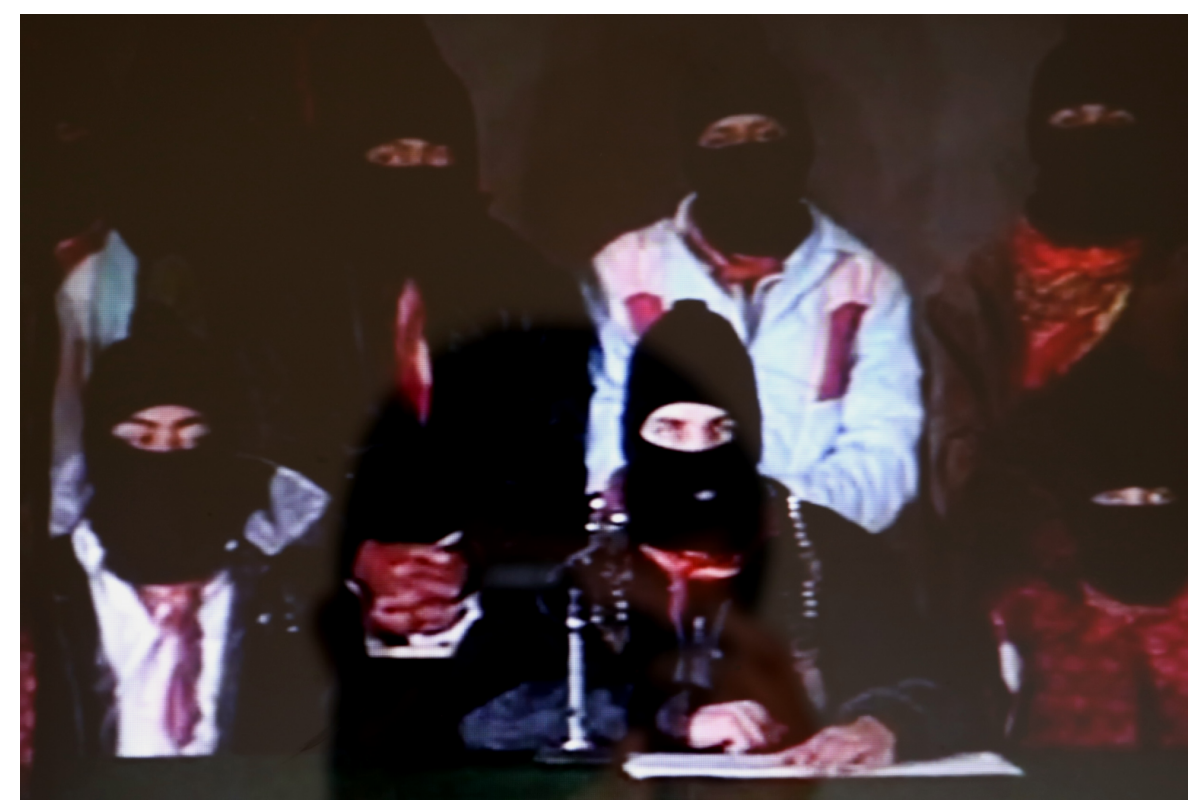

F2. Primeras pláticas para la paz. Irma Ávila, Chiapas: paisaje después de la batalla, 1994, $\min .54: 36$.

Otro de los momentos importantes de la lucha fueron las primeras pláticas para la paz que establecieron el EZLN y el gobierno mexicano, el 21 de febrero de 1994, 51 días después de haberse iniciado el conflicto. En dichas pláticas participaron Manuel Camacho Solís, representante del gobierno de México y, a petición de los zapatistas, el Obispo Samuel Ruiz. El acontecimiento es reconstruido con la integración de las imágenes de la salida y llegada de las y los comandantes zapatistas quienes arriban, en unas camionetas con pañuelos blancos en señal de paz, a la diócesis de San Cristóbal de Las Casas. En dichas pláticas se presenta el Subcomandante Marcos, acompañado de los comandantes, quien expresa su sentir: “¿qué ocurre en este país? Le hablamos a todos, a gobernantes y a gobernados, ¿Qué ocurre en este país que es necesario morir para poder decir unas palabras pequeñas y verdaderas sin que se pierdan en el olvido?” (min. 
54:36). Uno de los distintivos del filme es que no enfatiza la atención en la presencia y participación del Subcomandante Marcos, puesto que en pocos momentos de la película se insertan sus palabras. Hay una intención de dar relevancia a aquellas voces que antes no tuvieron el espacio ni los medios para pronunciarse.

Consecutivamente, la directora inserta imágenes del desplazamiento de cientos de hombres y mujeres, que huyen de sus comunidades por temor a ser agredidos, por la creciente presencia de los militares en diferentes puntos de Chiapas. En contraparte, y de manera coexistente, se insertan imágenes de la movilización de la sociedad civil en apoyo al EZLN, varios actores sociales salen en defensa de la lucha. Se expresa una incertidumbre: el triunfo o la derrota del movimiento, por ello, la directora integra las palabras de Sergio Sarmiento, del Instituto de Investigaciones Sociales de la UNAM, quien menciona el doble camino que puede tomar la lucha zapatista:

El impacto de las organizaciones indias a partir de la irrupción del ejercito zapatista pueden ser muy amplias en un escenario optimista. En el escenario pesimista, significaría que las fuerzas que se oponen en este país puede que [...] desechen las demandas de los indios [...] y se acallen los reclamos y que nuevamente las voces se queden gritando en la selva (min. 58:12).

La última escena de la película está compuesta por diferentes imágenes sobre los militares en las calles, el rostro de niños y niñas, el andar de hombres zapatistas, estas imágenes parecen interpelarse porque, por un lado, refieren a la presencia militar y al conflicto armado que parece no acabar y, por el otro, aluden a la esperanza de lograr los objetivos que persigue la lucha del EZLN. El documental que fue realizado en el primer año del levantamiento, no pudo dar cuenta del proceso que siguió en 1995 y en adelante, y eso se deja en claro con las últimas palabras de la directora, quien anhela que los diferentes sectores de la sociedad sean partícipes del acontecimiento:

Tomando en cuenta que la pacificación depende del seguimiento y concreción de los acuerdos, de la interrelación de los diferentes actores sociales participantes en el conflicto, y de nuestra capacidad como sociedad civil para 
no permitir que exista una paz como la de antes de 1994, dependerá de que haya un amanecer mucho más esperanzador en 1995 (min. 59:00).

\section{Autonomía zapatista. Otro mundo es posible}

El documental Autonomía Zapatista. Otro mundo es posible4 (2008), realizado por Cristina Hijar y el Colectivo Arte, Música y Video, es un material en el que las voces zapatistas son el principal eje conductor de la narrativa, acompañadas por varias secuencias de murales y consignas de lucha escritas sobre las paredes de las casas. Se integra, además, una abundante música de protesta. El filme está compuesto de tres bloques generales: el primero ofrece una síntesis de los tiempos que marcaron el andar de los primeros 10 años de la lucha zapatista en Chiapas; el segundo, presenta el nacimiento de las Juntas de Buen Gobierno y los Caracoles, el funcionamiento y organización comunitaria; y el tercero, socializa los trabajos que desarrollan los promotores zapatistas en sus comunidades. Por cuestiones de espacio, únicamente desarrollamos una reflexión sobre cinco puntos que se exponen en el material: el marco histórico, el surgimiento de las Juntas de Buen Gobierno (JBG), "la otra justicia", "la otra comunicación" y "la otra producción.

La película inicia con una secuencia de paisajes abiertos, de montañas y el salir del sol. Mientras la secuencia de paisajes continúa, se inserta la voz en off de uno de los integrantes de la Junta de Buen Gobierno del Caracol "Morelia": "para nosotros vimos necesaria la lucha porque vimos que no nos toman en cuenta el mal gobierno, nos trata como animal, sin derecho, y despreciados. Hoy seguimos luchando y gobernando entre nosotros para cambiar el mal sistema de los capitalitas del país" (min. 01:0o). Seguido de esta secuencia, aparece por primera vez, con voz en off, la narradora del documental, asume el papel de articuladora de las voces e imágenes, hace un repaso de los años de lucha del EZLN, enfatiza en la Primera Declaración de la Selva Lacandona, el anuncio de las once demandas zapatistas a las que después se agregarían, derecho a la cultura y comunicación. Uno de los

4 Disponible en línea: https://www.youtube.com/watch?v=o-DWXgROEMI 
elementos narrativos que distingue la película es la integración de fotografías de la portada de uno de los diarios nacionales más importantes de México: La Jornada. Se anexan las portadas y algunas notas que se emplean como recursos y sustento de memoria. La voz en off de la narradora nos sitúa en la siguiente fecha: 22 de febrero al 2 de marzo de 1994, día en que se dan las primeras conversaciones de la paz en la Catedral de San Cristóbal de Las Casas. Luego nos traslada a la fecha en que se dio a conocer "La segunda declaración de la Selva Lacandona”, el 12 de junio de 1994, tiempo en el que se anuncia la convocatoria para la Convención Nacional Democrática.

La voz en off de la narradora continúa y nos sitúa en la fecha en que se da a conocer "La Tercera Declaración de La Selva Lacandona”, el primero de enero de 1995, en la que se propone un Movimiento de Liberación Nacional encabezado por la Convención Nacional Democrática. Posteriormente, se insertan imágenes del inicio de los Acuerdos de San Andrés, realizados entre octubre de 1995 y febrero de 1996. Aparece una secuencia de las mesas, el cerco de la cruz roja y los voluntarios. todas las imágenes son de archivo fílmico y fotografías de periódicos. Más adelante, se insertan los testimonios y grabaciones inéditas de los sobrevivientes de la masacre en Acteal, perpetrada el 22 de diciembre 1997. Mientras se escucha el relato de uno de los señores, se presentan imágenes de una peregrinación en la comunidad: "cuando nosotros nos enteramos que habían enfrentamientos empezamos a hacer oración [...] ya van casi tres días de ayuno para pedir la paz y la tranquilidad aquí en el municipio de Chenalhó [cuando] llegaron los paramilitares a masacrar a los 45 hermanos” (min. 06:10).

La narradora nos sitúa en "La Quinta Declaración de la Selva Lacandona”, pronunciada el 19 de julio de 1998, en el inicio de la Marcha del color de la Tierra y la Dignidad indígena hacia la ciudad de México, el 24 de febrero de 2001, en el pronunciamiento de la comandanta Esther en el congreso, el 28 de marzo de 2001, su intervención es presentada a cuadro: "cuando se reconozcan constitucionalmente los derecho y la Cultura indígena, de 
acuerdo con la iniciativa de Ley de La COCOPA5, la Ley empezará a unir su hora a la hora de los pueblos indios" (Min. 08:43). Y, finalmente, la secuencia culmina con el pronunciamiento del EZLN, realizado el primero de enero de 2013, quien condena la traición de los tres principales partidos políticos a los Acuerdos de San Andrés. Este primer apartado del documental busca visibilizar el caminar de las y los zapatistas y, al mismo tiempo, exponer el desinterés del Estado mexicano, la impunidad, la injusticia y su falta de sensibilidad para atender las demandas que exigían los pueblos en lucha.

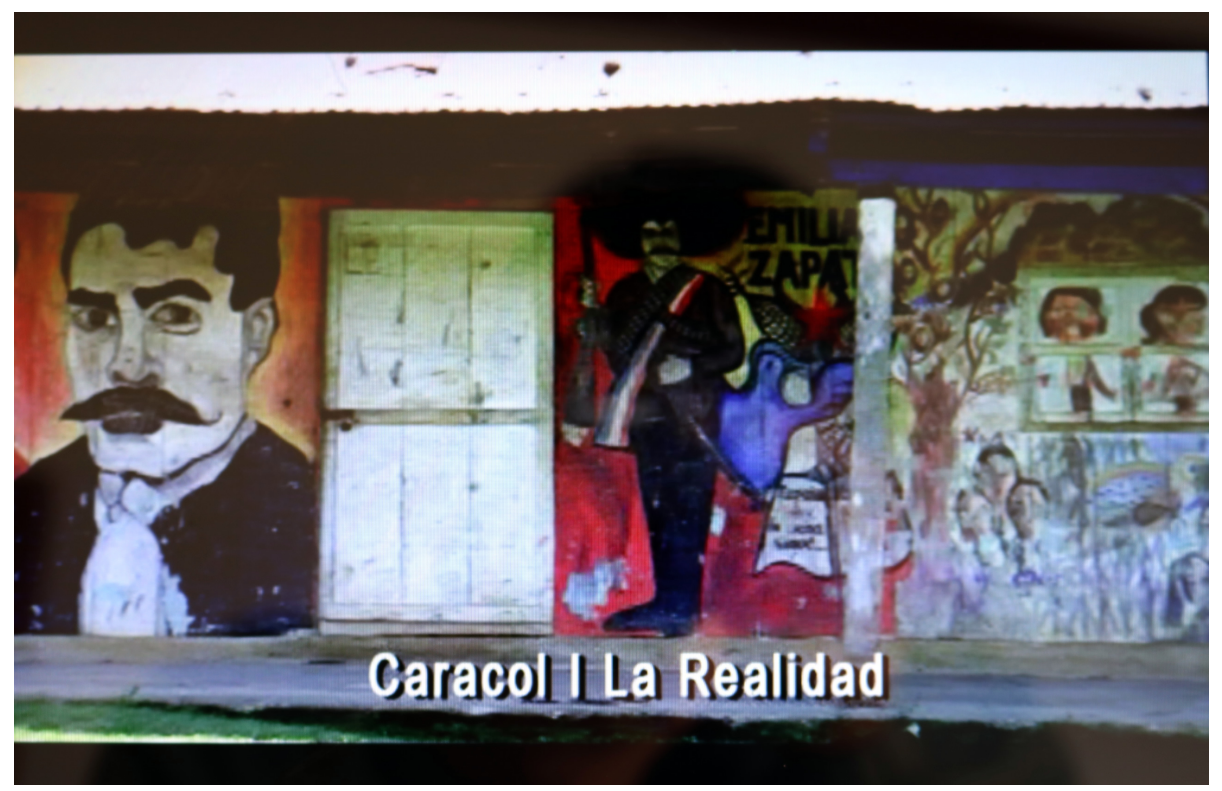

F3. Mural en el Caracol "La Realidad". Cristina Hijar y Colectivo AMV, Autonomía Zapatista. Otro mundo es posible, 2008, min. 12:o9.

La segunda parte del documental inicia con el anuncio del EZLN sobre la desaparición de Los Aguascalientes para dar nacimiento a los cinco Caracoles $^{6}$ y las Juntas de Buen Gobierno, el 8 de agosto de 2003. Éste fue uno de los grandes acontecimientos de la lucha política y de autonomía zapatista; se presenta, con voz en off, la reflexión de la comandanta Rosalinda, que es acompañada de imágenes de los mítines en los Caracoles:

5 La COCOPA es la Comisión de Concordia y Pacificación, integrada por legisladores de las cámaras federales y el Congreso local. Véase el siguiente enlace para mayor información: https://sipaz.wordpress.com/tag/ley-cocopa/

${ }^{6}$ Los caracoles son: Caracol I, La realidad; Caracol II, Oventic; Caracol III, La Garrucha; Caracol IV, Morelia; y Caracol V, Roberto Barrios. 
Compañeros y compañeras hoy estamos demostrando, una vez más, que somos fuerte para luchar, nuestra principal arma de lucha ahora es nuestra resistencia, y nuestra organización de todos los pueblos, por eso estamos aprendiendo a construir nuestra autonomía, ya sabemos formar nuestros municipios autónomos y también ya tenemos las Juntas de Buen Gobierno (min. 10:50).

Las secuencias siguientes corresponden a la presentación de cado uno de los Caracoles, acompañadas de diferentes imágenes de los murales, de mujeres trabajando, de las y los jóvenes en las comunidades. Se insertan, además, fotografías fijas de los encuentros y talleres de capacitación. Uno de los zapatistas del Caracol "Morelia" expresa la importancia de las JBG y cómo trabajan: "esta forma de gobierno es diferente que el gobierno oficial, gobernamos al pueblo y también obedecemos de todas sus opiniones, es decir, mandar obedeciendo" (min. 15:47). En otro momento, se presenta la participación de una compañera zapatista de "La Realidad", quien comparte las actividades que llevan a cabo con sus compañeros de la Junta:

En cada Junta funciona una comisión de vigilancia, igualmente rotativa y nombrada por asamblea [...] tienen a su cargo obtener los datos de quienes desean presentar asuntos a la Junta, clasificar todo tipo de problemas y pasarlos a la instancia adjunta de Gobierno, la comisión de vigilancia también está presente para que la Junta no se vaya por el mal camino (min. 21:52).

Mientras se escucha la participación de las y los zapatistas, se insertan varias fotografías de los documentos sobre los acuerdos, los permisos, los donativos y la entrega de materiales que las JBG expiden, sellan y firman a las comunidades y visitantes. Se enfatiza en el trabajo colectivo y colaborativo entre las autoridades zapatistas y las comunidades autónomas.

El tercer bloque del documental inicia con la presentación de las formas de integración y participación comunitaria autónoma que, en palabras de León (2010), expresa la existencia de “otras epistemologías”, las mismas que se comparten por temáticas: la otra justicia, los derechos humanos, la otra comunicación, la otra educación y la otra producción. Varios compañeros zapatistas explican brevemente cómo se aplica "la otra justicia": 
El que comete un delito recibe un castigo, de acuerdo con todo el pueblo, si acaso es que robó algo, entonces lo hacemos que lo devuelva y así queda libre [...] lo más que hemos visto ahora son problemas agrarios, problemas familiares tales como divorcios o maltrato. Hay problemas de violación de los derechos humanos que sucede en otros municipios, entonces aquí vienen a quejarse para ver en qué forma se pueden reparar los daños (min. 27:10).

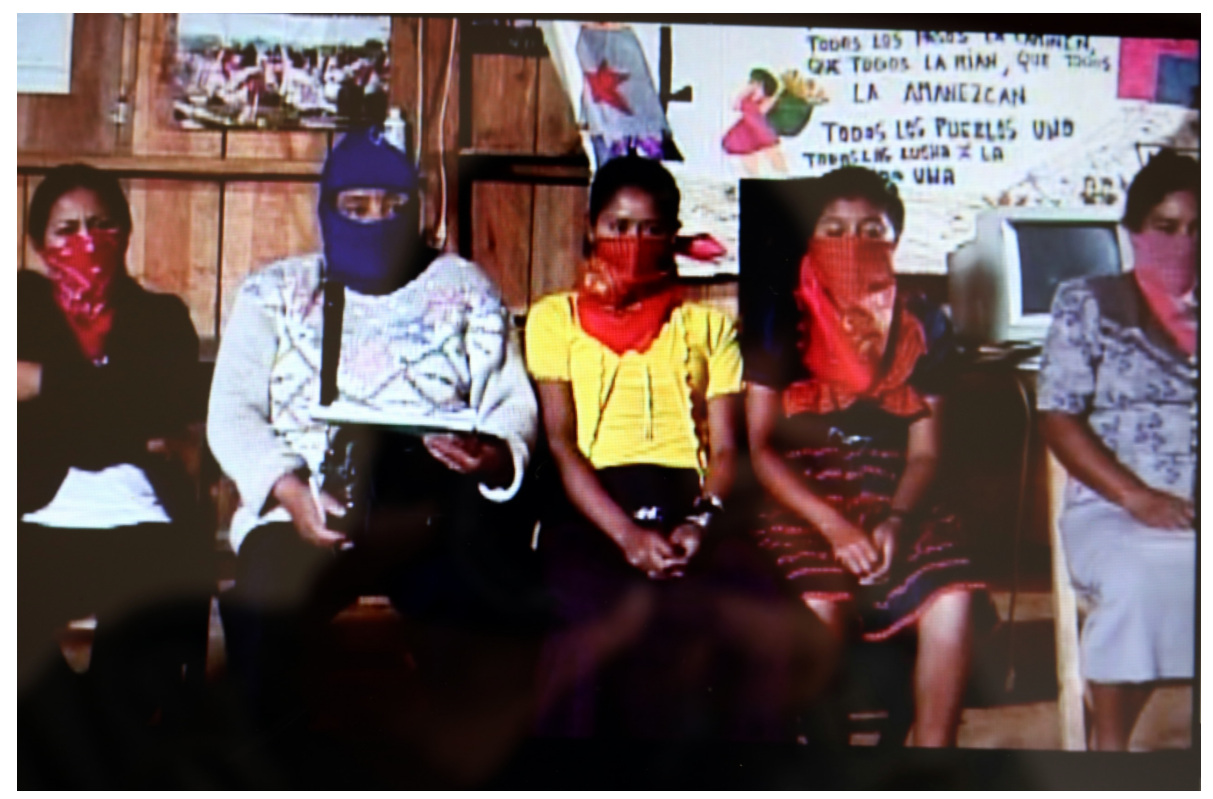

F4. Mujeres zapatistas. Cristina Hijar y Colectivo AMV, Autonomía Zapatista. Otro mundo es posible, 2008, min. 39:25.

Uno de los elementos que destaca sobre la construcción y aplicación de "la otra justicia” es que demuestra que los problemas no terminan y que existen aún en la autonomía. Sin embargo, la aplicación de las reglas socialmente aceptadas en la búsqueda de justicia es, a nuestro parecer, un logro conseguido por los años de lucha. Lo anterior se expresa con el respeto a los derechos humanos. Al respecto, una mujer zapatista comparte su experiencia sobre el lugar de la mujer en las comunidades autónomas, mientras la escuchamos, se inserta una secuencia de imágenes sobre la participación de la mujer en las asambleas, en los movimientos, su representación en los murales, y canción de fondo sobre el trabajo y el maltrato de la mujer refuerza el relato:

La participación de las mujeres, principalmente como autoridad, aquí nosotros en la Junta de Buen Gobierno pues nada más habemos dos mujeres, 
pero una está en cada turno, entonces para mí, pues, lo veo poco, y en cuestión de educación lo veo bajo lo que es la participación de la mujer, y donde está más avanzando es en lo de salud, allí si hay más participación (min. 30:40).

La tercera temática, "la otra comunicación", alude a las tecnologías audiovisuales y de comunicación que disponen los zapatistas. En una escena se presenta al Comandante David quien explica la importancia de la radio: "las radios comunitarias han servido para educar a la gente, para orientar y dar mensajes que el pueblo realmente necesita” (min. 43:00). Más adelante se presenta el testimonio de otro compañero: "una radio comunitaria es un arma potente, no para destruir sino para construir conciencia” (min. 45:07). Los relatos de ambos zapatistas son recreados con la integración de imágenes fijas de las antenas, las cabinas de radio, las mesas de reunión y de los murales sobre la “otra comunicación”. En este apartado, se expone el papel que juega la cámara de video y el sentido político que le adjudican. Se anexan los trabajos que han realizado los realizadores audiovisuales zapatistas:

Empezamos a aprender a grabar las imágenes a través de una cámara, para saber un poquito de cómo estamos viviendo en la resistencia, cómo estamos construyendo nuestra autonomía, si en una comunidad autónoma quieren mostrar algo de salud, pues entonces hay que grabar (min. 47:09).

Otro compañero zapatista señala que "la comunicación es para nosotros el intercambio de conocimiento. Sirve para testimoniar todo lo que está pasando en las comunidades en resistencia” (min. 48:15). Hay un sentido político adjudicado a las herramientas audiovisuales y a los contenidos que realizan.

El último apartado sobre "la otra producción", alude a la forma organizativa de trabajo colectivo y de producción de los productos y alimentos orgánicos, en las comunidades autónomas zapatistas. En el filme se anexa el testimonio de don Santiago, del Comité de Desarrollo: "aquí hay varios colectivos de puercos, de panadería, de pollo, y algunas tiendas de molino, algunos que trabajan de ganado y de peces" (min. 58:12). Se muestran las tiendas y cooperativas que tienen, sobre las paredes, mensajes alusivos a la lucha. Se presenta el testimonio de otro compañero zapatista: "ya tenemos 
cooperativas de artesanías, de café [...] ahorita ya hay dos cooperativas de café, está la cooperativa Mutvitz y yach’il xojobal” (min. 58:41).

En términos generales, el documental es un recurso y un medio para socializar el proceso, el caminar, los logros y los nuevos desafíos que enfrentan las y los zapatistas. Aún cuando el gobierno mexicano se desinteresara de la lucha e hiciera caso omiso a sus demandas, el EZLN marcó su propio rumbo en el que es visible en términos materiales, filosóficos y políticos, reconocer la construcción de su autonomía y que, además, continúa en constante configuración y replanteamiento, con el ideal claro de construir su autonomía con el "mandar-obedeciendo".

\section{Los hombres sin rostro}

Uno de los filmes sobre la lucha zapatista, de reciente producción, es Los hombres sin rostro ${ }^{7}$ (2016), de Elena Korykhalova y Oleg Myasoedov, originarias de Rusia. El documental tiene la particularidad de presentar las acciones que ha realizado el EZLN entre el 2014 y el 2016. Recupera el testimonio de la ciudadanía, de académicos, de defensores de derechos humanos y de las víctimas de los conflictos recientes, que más adelante se exponen. En la primera secuencia de la película se presenta, a cuadro fijo y cerrado, el sentir de un zapatista quien, reunido con otros compañeros, menciona: "antes de la colonización nuestros pueblos tenían sus propias formas de vivir, sus modos de ver el mundo, de ver la vida, pero con la llegada de la colonización, se pierde todo, le imponen otro modo de vida, otro modo de pensar, nosotros los pueblos logramos conquistar nuevamente nuestra libertad" (min. o0:15). Esta secuencia presenta a un zapatista, como muchos, que tiene interiorizado una postura política y de conocimiento histórico, que le permite comprender el presente y el sentido de su lucha.

El filme se apoya en una narradora que aparece con voz en off, quien ofrece datos estadísticos sobre la diversidad lingüística en México, la condición económica, la situación de pobreza y marginación en los estados del Sureste

7 Disponible en línea: https://www.youtube.com/watch?v=NqlZOa7DMiU 
del país, con un mapa interactivo que contextualiza la información ofrecida. El documental comienza el planteamiento con una secuencia de imágenes de uno de los encuentros zapatistas realizados en el CIDECI-Uniterra ${ }^{8}$, localizado en San Cristóbal de Las Casas, donde hombres, mujeres, niños y niñas aparecen. De manera paralela, se insertan algunas imágenes de archivos fílmicos 9 de las primeras grabaciones del EZLN. Mientras vemos las imágenes, se inserta la voz en off del Subcomandante Marcos: "lo que para nosotros inicia en 1994 es uno de los muchos momentos de la guerra de los de abajo contra los de arriba, es una guerra por la humanidad, contra el neoliberalismo" (04:59). De pronto se hace un salto espacio-temporal, donde aparece nuevamente el Sub Marcos, quien menciona por primera vez el nombre del movimiento armado en 1994: "es un movimiento de insurrección que se llama Ejército Zapatista de Liberación Nacional” (min. 05:30).

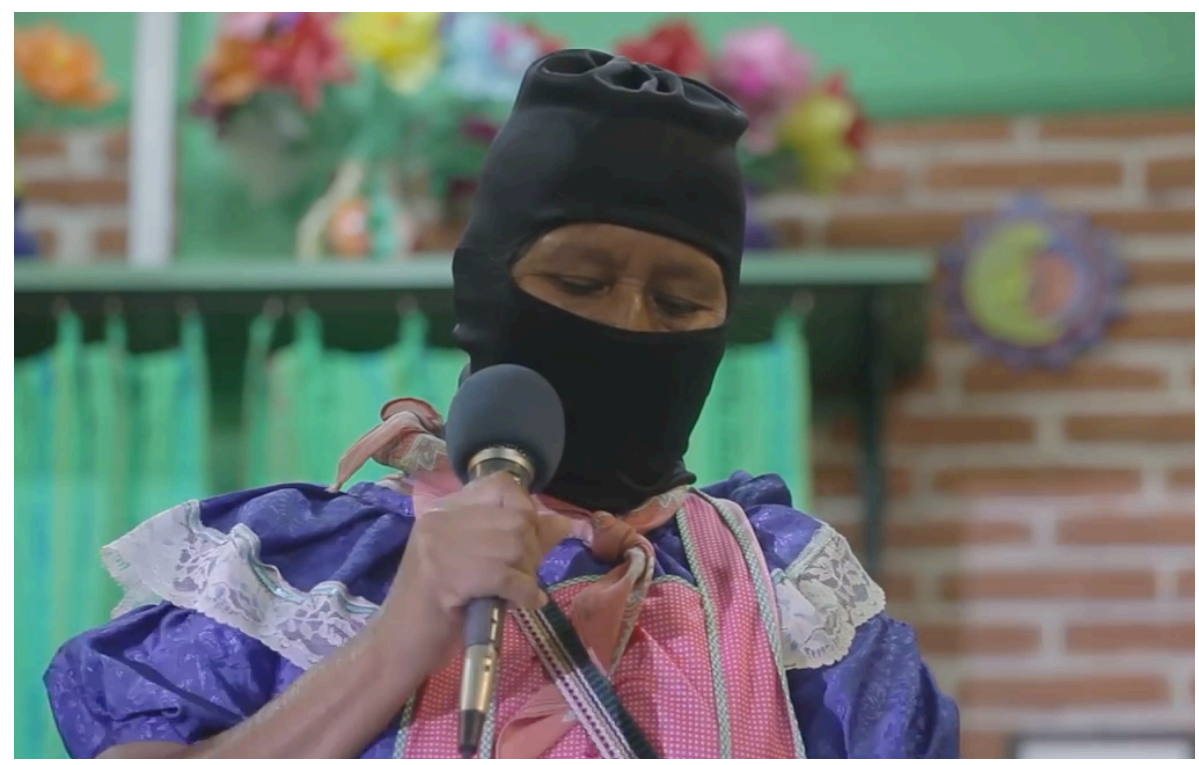

F5. Palabras de una mujer zapatista. Elena Korykhalova y Oleg Myasoedov, Los hombres sin rostro, 2016, min. 12:15.

El documental realiza varios saltos espacio-temporales, sin hacer un relato cronológico. En una de las escenas consecutivas, se escucha y presenta a un ex militar, que conduce un taxi de servicio público, quien da constancia de su sentir: "anteriormente los indígenas no tenían voz ni voto, no fungían en esta

8 Véase la página del CIDECI-Unitierra: http://seminarioscideci.org/

$9 \mathrm{El}$ archivo fílmico integrado a la narrativa fue tomado de las imágenes que se presentan en la película Zapatistas: crónica de una rebelión (La Jornada y Canal 6 de julio, 2004). 
sociedad, había mucho caciquismo, el cacique es gente que tiene mucha tierra y les daba trabajos temporales a los indígenas, eso existió por muchos años y décadas aquí en Chiapas” (min. 06:30). Posteriormente, el filme nos traslada a las instalaciones del Centro Indígena de Capacitación Integral (CIDECI), donde se presentan las voces y testimonios de zapatistas, defensores de derechos humanos, activistas y asistentes al Congreso Nacional Indígena (CNI). Se muestran las mesas de trabajo y pequeños fragmentos de los participantes. Una mujer zapatista se pronuncia en lo alto del templete: “como Ejército Zapatista de Liberación Nacional hacemos nuestro todo lo que está pasando en todos los rincones de nuestra patria mexicana, tenemos que defendernos [...] sin importar las consecuencias" (min. 12:15).

Las directoras cambian radicalmente de tiempo y lugar, y graban una charla establecida en las Instalaciones de Derechos Humanos"10 "Fray Bartolomé de Las Casas" (El Frayba) en San Cristóbal de Las Casas, donde una de las integrantes de dicha institución ofrece una plática resumida de lo que ha sido la lucha del EZLN y los diversos problemas que se han suscitado en Chiapas, y de los voluntarios que reciban para hacer trabajo en comunidades autónomas. Súbitamente se da otro salto, al situarse en Acteal, Chiapas, lugar donde se cometió una de las masacres más crueles en la historia reciente de México. En el lugar se muestran las marcas de las balas que perforaron las paredes de madera, marcas que jamás se olvidaron, que jamás cicatrizaron y que son significados como recursos de la memoria colectiva de Acteal, que son compartidos durante la rememoración social el día 21 de diciembre de cada año. La cámara se introduce hasta el salón donde fueron sepultados los cuerpos de los 45 hombres y mujeres asesinadas. Uno de los habitantes de Acteal comparte su testimonio: "los hombres y mujeres que se quedaron aquí [señala una casa], pues allí se le cayó el cuerpo por la balacera, allí se quedaron amontonados todos los 45 que se murieron” (min. 15:40). Se aprecian las fotografías, las cruces, sus nombres, las flores, las velas y un mural que alude a la muerte y a la vida, es su lugar de memoria. La narración se traslada, nuevamente, a otro momento de la historia zapatista, al integrar

10 Para conocer el trabajo del Frayba sugerimos que visiten su página oficial: https://frayba.org.mx/ 
imágenes de archivo fílmico de la primera reunión nacional realizada en un Aguascalientes.

La integrante de "El Frayba" se convierte en cronista del documental al ser quien ofrece los puntos y lugares donde la narrativa se centra para recrear y presentar las imágenes de lo que se dice. Uno de estos es la creación de Los Caracoles, se escucha la voz de un compañero zapatista, quien explica por qué decidieron llamarle Caracoles: "tomamos lo que hace el animalito, porque ese animalito camina lento, avanza, va avanzando, y eso mismo es lo que retomamos nosotros los zapatistas, porque nuestra lucha va caminando lento, pero sí va avanzando" (min. 20:20). De nueva cuenta, el documental se centra en la situación de las familias desplazadas del ejido Puebla11, Chenalhó. Se ven los rostros desencajados de los hombres, mujeres, niños y niñas afectadas por el conflicto político. Uno de los señores víctima del desplazamiento forzado comparte ante la cámara su sentir: "tuvimos que salir por tantas amenazas de muerte, no lo aguantamos con ese dolor que nos hicieron" (Min. 22:55). Es importante señalar que en Chenalhó se han generado y agudizado el uso de la violencia desde 1997, derivado de conflictos postelectorales, por problemas agrarios y territoriales. En varios testimonios se señala la presencia de grupos paramilitares ${ }^{12}$, acontecimiento que busca visibilizarse en los relatos que compone la narrativa del documental.

En la escena consecutiva, se presenta una breve nota sobre el asesinato del maestro zapatista Galeano ${ }^{13}$. Varios hombres y mujeres caminan alrededor de la tumba de Galeano, cada uno y una lleva una pequeña piedra a la que colocan sobre ésta; al fondo aparecen los periodistas que registran el acto luctuoso. El maestro fue sepultado en el Caracol "La Realidad". A continuación, se anexan imágenes de un encuentro zapatista en el Caracol

${ }_{11}$ Para saber sobre el conflicto en el ejido Pueblo, Chenalhó, sugerimos que revisen el siguiente enlace: https://frayba.org.mx/tag/desplazamiento-puebla/

12 Véase Vega, Andrea (4 de abril, 2018). De la religión al territorio y a la política: la violencia que mina la vida en Los Altos de Chiapas. Animal Político,

https://www.animalpolitico.com/2018/04/religion-territorio-politica-la-violencia-quemina-los-altos-chiapas/

13 Véase la siguiente crónica para conocer sobre la historia y el asesinato del maestro Galeano: http://radiozapatista.org/?p=12813 
mencionado. Varios zapatistas marchando, y algunos montados en su caballo, se presentan a la mitad de la cancha, saludan a los presentes. Mientras vemos las imágenes del encuentro, se escucha la voz del Subcomandante Marcos, quien anuncia una de las noticias que más inquietud causó en la opinión pública y en los medios de comunicación: “como se ha demostrado en estos 20 años [...] el caso es que el sub pasó de ser un vocero a ser un distractor, el personaje fue creado y ahora sus creadores los zapatistas y las zapatistas lo destruimos" (min. 29:30). El sub Marcos aparece a la mitad del campo, pasea montado en su caballo. En seguida varios zapatistas hacen guardia y saludan a las cuatro esquinas, ritual de presentación que llevan a cabo en cada acto inaugural. Más adelante, Aparece el Subcomandante Moisés, quien se expresa desde el templete, les menciona a los presentes, anticipadamente, que Galeano está próximo a resucitar: "porque lo más importante para nosotros son las y los compañeros de los pueblos, ellos son nuestra fuerza, nuestro alimento, nuestro destino, ellos somos nosotros. Compañeras y compañeros venimos a desenterrar al compañero Galeano, al rato lo van a ver" (min. 32:33).

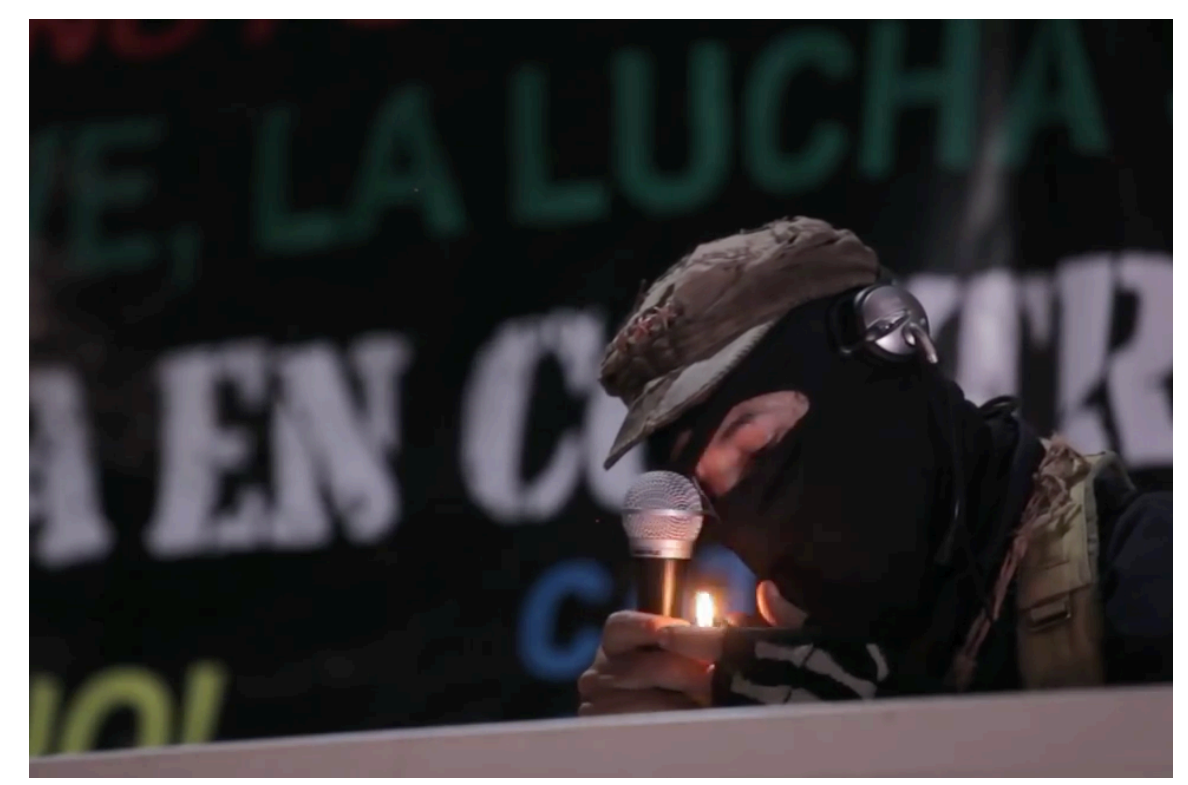

F6. La muerte del subcomandante Marcos. Elena Korykhalova y Oleg Myasoedov, Los hombres sin rostro, 2016, min. 33:38. 
Seguido de la escena anterior, el Subcomandante Marcos aparece sentado, tomando una hoja, le da lectura, anuncia al fin su muerte: "pensamos que es necesario que uno de nosotros muera para que Galeano viva, así que hemos decidido que Marcos deje de existir hoy" (Min. 33:27). deja de leer, enciende su puro, se levanta sin decir una sola palabra y se retira de la mesa. Se dibuja un silencio profundo, nadie de los presentes dice nada, el viento se suspende. Un fondo negro aparece, y una canción armoniza la muerte de Marcos. El acontecimiento es una muerte simbólica, de nombre, más no física, que en términos ideológicos y políticos supone la reivindicación de un personaje importante para la historia del zapatismo, a quien necesitan mantener presente en nombre, encarnado en el cuerpo de alguien que, en palabras del Sub Marcos, es una creación zapatista. No obstante, la muerte simbólica no implicó un cambio de fondo en los paradigmas de la lucha del EZLN, pero sí en términos de quién sería ahora uno de los voceros de la lucha: El Subcomandante Galeano. Asimismo, la decisión demuestra que los zapatistas tienen la voluntad y el control de hacer morir a quien consideren, para dar vida a aquellos que jamás desean olvidar, que se traduce en un gesto político de memoria.

Posteriormente, se presenta la realización de "La escuelita"14, una de ellas en el CIDECI. La otra, en una comunidad de la selva. Cabe señalar que ésta iniciativa de los zapatistas surge con la finalidad de permitirnos conocer el trabajo que han realizado en sus años de lucha, mediante contenidos y materiales que ellos y ellas mismas desarrollan. Más adelante, se construye una secuencia de imágenes de hombres y mujeres, principalmente de otros países, que hacen su equipaje para comenzar su viaje al Caracol "La Garrucha”, la cámara se sube a la camioneta y hace el registro de todo el camino. Se presentan las veredas, las casas que están a su paso y también la base militar, ubicada en las profundidades de la selva en Chiapas. Al llegar, los visitantes reciben una clase de jóvenes zapatistas que comparten sus reflexiones. Uno de ellas, toma la palabra y expresa su sentir:

\footnotetext{
14 Para conocer más sobre "La Escuelita" sugerimos el artículo de Zagato, Alessandro y Arcos, Natalia (2017). "El Festival 'Comparte por la Humanidad'. Estéticas y poéticas de la rebeldía en el movimiento zapatista”. Páginas, núm. 21, pp. 74-101.
} 
Desde un principio lo malos capitalistas nos vienen diciendo que las mujeres no saben nada, pero no es cierto compañera. Que nosotras las mujeres no sabemos leer, ni escribir, ni hablar la segunda lengua, lo que es la castía. Compañeras nosotras también podemos ocupar cargo y este, buscando formas de cómo mejorar más la participación de las mujeres (min. 41:12).

La última escena del filme es una presentación de rostros de hombres y mujeres tsotsiles de Zinacantán, los rostros parecen materializarse como una metáfora del rostro presente de la lucha. Es la cara del dolor, de la sinceridad, de la esperanza, de la juventud, de la niñez, de los ancianos, de las nuevas generaciones. Los rostros de los 20 años de lucha zapatista.

\section{Conclusiones}

Los filmes analizados tienen constantes y también particularidades sobre lo que se dice de la lucha zapatista. La primera es que ubican su atención en las palabras de las mujeres y los hombres zapatistas quienes, de no ser por su irrupción, difícilmente habrían encontrado y habilitado un lugar y medio de expresión. La segunda, es que integran varios testimonios y experiencias de vida mediante el recurso de la voz en off, pocas veces se presentan a los zapatistas frente a la cámara, más bien, se recrean sus palabras con imágenes que refuerzan lo que expresan. La tercera, es que buscan reivindicar la lucha, los motivos del levantamiento y los logros que ha obtenido el EZLN, en este sentido, no se victimiza al movimiento, al contrario, se deja constancia de la autonomía y la forma de gobierno que han logrado consolidar. Otra característica que comparten es que no recurren a los archivos fílmicos de la parte oficial del Estado mexicano, es decir, no se presentan las voces de los presidentes ni el de la clase política. Esta decisión no es gratuita, puesto que se busca, ante todo, socializar las vivencias de las comunidades en lucha, son ellos los agentes de cambio.

Los filmes comparten la singularidad de estar a disposición del público, puesto que pueden ser visualizados en YouTube. Esto, consideramos, responde a una estrategia de difusión y comunicación puesto que, generalmente, los filmes de la lucha zapatista no son realizados para 
competir en los festivales de cine, ni para ganar premios, no son hechos con una lógica mercantil. En este sentido, las producciones son independientes, con el consenso de Los Caracoles y las JBG, puesto que son ellos los que toman la última palabra en permitir la entrada de las cámaras. Ello incide en el tratamiento narrativo y visual al que recurren las y los realizadores. Se manifiesta una cercanía, un sentido de pertenencia y vínculos que establecen con la lucha zapatista. Las películas citadas, así como la mayoría de los filmes zapatistas, difícilmente acceden a las salas y pantallas de cine comercial en México, sus canales de difusión, distribución y proyección se basan en pequeñas cooperativas, al interior de Los Caracoles, en universidades, en salas de cine independientes $\mathrm{y}$, como ya mencionamos, por medio del internet.

Consideramos que estas películas amplían los campos discursivos de lo que se dice y cree de la lucha zapatista, ofrecen, a partir de distintos momentos históricos grabados, un acercamiento al movimiento, por lo que se logra apreciar, desde otro lugar de enunciación, fuera de la óptica estatal. Ello nos lleva a concluir que dichos filmes se significan como objetos de la memoria, en tanto adquieran un sentido y valor simbólico que constituyen puentes y lazos que unen a una generación con otra, no sólo para las y los zapatistas, sino para quienes siguen, seguimos, su lucha.

\section{Referencias bibliográficas}

Aumont, J. y Michel, M. (1990). Análisis del film. Barcelona: Paidós

Casetti, F. y de Chio, F (1990). Cómo analizar un film. Barcelona: Paidós.

Centro de Derechos Humanos Fray Bartolomé de Las Casas (2014). Boletín del Desplazamiento del Ejido Puebla. Recuperado en https://frayba.org.mx/tag/desplazamiento-puebla/

Halkin, A. (2006). Fuera de la óptica indígena: Zapatistas y Videístas Autónomos. Revista Chile de Antropología visual, núm. 7, pp.71-92.

Hernández, L. y Vera, R. (1998). Acuerdos de San Andrés. México: ERA

León, C. (2010). Visualidad, medios y colonialidad. Hacía una crítica decolonial de los estudios visuales. En La Tronkal (coord). Desenganche, visualidades y sonoridades otras (pp. 33-52). Quito: La Tronkal. 
Leyva, X. y Köhler, A. (2016). Las guerras, la otra política y los medios indígenas en movimiento. En García, M.; Solís, J. y Uc, P. (Coords.) Democracias posibles: crisis y resignificación. Sur de México y Centroamérica (pp. 313-338). México: UNICACH.

Mitchell, J. (2009). Teoría de la imagen. Ensayos sobre representación verbal y visual. Chicago: Universidad de Chicago.

SIPAZ (Febrero de 2014). Chiapas: a 18 años de la firma de los Acuerdos de San Andrés sobre Derechos y Culturas Indígenas, estos continúan sin ser reconocidos por el estado mexicano. Recuperado en: https://sipaz.wordpress.com/tag/ley-cocopa/

Subcomandante Insurgente Galeano (mayo de 2015). Maestro zapatista Galeano. Apuntes de una vida. Recuperado en: http://radiozapatista.org/?p=12813

Vázquez, F. (2001). La memoria como acción social. Relaciones, significados e imaginarios. Barcelona: Gedisa.

Vega, A. (4 de abril, 2018). De la religión al territorio y a la política: la violencia que mina la vida en Los Altos de Chiapas. Animal Político, https://www.animalpolitico.com/2018/04/religion-territoriopolitica-la-violencia-que-mina-los-altos-chiapas/. Fecha de consulta: 10 de julio de 2018.

Zagato, A. y Arcos, N. (2017). El Festival 'Comparte por la Humanidad'. Estéticas y poéticas de la rebeldía en el movimiento zapatista. Páginas, núm. 21, pp. 74-101.

\section{Filmografía}

Ávila, I. (1994). Chiapas: paisaje después de la batalla. México: TV UNAM.

Hijar, C. y Colectivo AMV. (2008). Autonomía Zapatista. Otro mundo es posible. México: Arte, Música y Video S.A de C.V

Korykhalova, E. y Myasoedov, O. (2016). Los hombres sin rostro. MéxicoRusia: Independiente. 